* Doutorado em Direito pela Pontifícia Universidade Católica de São Paulo, B r a si 1 ( $\left.\begin{array}{llll}1 & 9 & 9 & 9\end{array}\right)$. lourivaloliveira40@ hotmail.com

** Mestrando em Administração- PPGA-Universidade Estadual de Londrina, Especialização Marketing FGV e Graduação em Economia pela mesma instituição. mluismassaro @gmail.com

\section{As mudanças contemporâneas no mundo do trabalho e o princípio da valorização do trabalho humano}

\author{
THE CHANGES CONTEMPORARY IN THE WORLD \\ OF WORK AND THE PRINCIPLE OF VALUATION OF \\ HUMAN WORK
}

* Lourival José de Oliveira

** Marcio Luis Massaro

Resumo: Este artigo busca apresentar as principais mudanças ocorridas no modo de produção contemporâneo, advindas do que se convencionou ser a $3^{\mathrm{a}}$ Revolução Industrial, combinado ao advento de pressupostos político-econômicos neoliberais, e as consequencias desse novo contexto para o mundo do trabalho. O foco principal de análise parte dos ditames do art. 170 da Constituição Federal Brasileira que funda a ordem econômica na valorização do trabalho humano como meio de promoção da dignidade da pessoa humana. A tese confirmada, é de que as condições impostas pelo novo paradigma produtivo, fere diretamente princípios constitucionais fundamentais.

Palavras-chave: Desestruturação; Mundo do trabalho; Dignidade da pessoa humana.

Abstract: This paper, aims to disclose, the main changes which ocurred within the comtemporary production standard, due to what has been estabilished during the third Industrial Revolution, togheter with the political economic neoliberal presuppositions and the outcomes in this new world of work. The main focus of this analysis, starts from the principles of the clause 170, of the Brazilian Federal Constitution, wich founded the economic order, based on the human labor as a mean to promote the human dignity itself. The confirmed thesis, is that, the conditions imposed by the new production standard, affects directly, fundamental constitutional principles.

Keywords: Disruption; World of work; Human being's dignity. 


\section{INTRODUÇÃO}

É evidente que há uma percepção generalizada, a nível global, acerca das mudanças por que passou o mundo do trabalho nas últimas décadas, em especial na América Latina, e mais precisamente no contexto brasileiro para o escopo desse trabalho.

A globalização econômica e o advento da chamada $3^{a}$ Revolução Industrial, proporcionaram aumentos expressivos da produtividade mecanizada, com consequentes transformações na forma e na disponibilidade de postos de trabalho em todo o mundo. No caso do Brasil, a exemplo de outras partes do globo, boa parte da população foi relegada à situação de desalento social, em especial pelo desaparecimento de postos de trabalho tradicionais e pela modernização rápida dos novos postos que surgiram, demandando um novo tipo de trabalhador mais especializado e ao mesmo tempo multifacetário.

Há um sentimento universal que o desemprego arraigado na sociedade moderna esteja contribuindo contumaz ao avultamento da pobreza, não obstante, a qualidade dos postos de trabalho existentes diminuiu, conforme corrobora Singer (2003, p. 11) na citação que segue:

Todo mundo, no mundo inteiro, fala do desemprego. A falta de bons empregos - de empregos que pagam e oferecem estabilidade, perspectiva de carreira, seguro-desemprego, seguro contra acidentes, enfermidades, velhice e morte é sentida em praticamente todos os países desenvolvidos e semidesenvolvidos. [...] É provável porém, que o desemprego esteja contribuindo para o avultamento da pobreza.

Como afirma Singer (2003, p. 15) a década de 1970/80 obteve rápido crescimento econômico, "nesse período a proporção de empregados de firmas particulares passou de $41,7 \%$ para $52,2 \%$, a de empregados públicos de 7,3 para 8,8, ao passo que a de autônomos caiu de 33,8\% para $25,2 \%$ e a de não remunerados de 9,9\% para 5,3\%." Os dados corroboram o período tido como "Milagre Econômico", referindo-se ao crescimento econômico observado não somente na área do emprego, mas, na economia brasileira como um todo.

Entretanto, a despeito do crescimento econômico observado na década de 1970/80 com criação e avanços na questão do emprego, a partir da segunda metade da década de 1980, o cenário econômico obteve resultado contrário, com reflexos negativos para o mundo do trabalho. A questão que se põe, refere- 
se às causas envolvidas com o fato. Em sua análise, Singer (2003, p. 16) questiona:

A grande indagação a este respeito é a seguinte: deve-se atribuir o ressurgimento do desemprego em escala crescente em quase todos os países capitalistas apenas à voga do liberalismo e ao consequente abandono das tentativas de preservar o pleno emprego mediante políticas Keynesianas, ou deve-se atribuí-lo também às transformações econômicas ocasionadas pelo conjunto de mudanças tecnológicas conhecidas como Terceira Revolução Industrial e pela crescente globalização das atividades econômicas?"

Não obstante às transformações econômicas e suas consequências na questão do emprego, Gomes (2003a, p.92) chama a atenção para uma tendência na virada do milênio no sentido de se institucionalizar o "conceito da democracia como fundamento da economia de mercado em detrimento da soberania popular, afastando-se os ditames da justiça social como fim da ordem econômica". Implica dizer que estando o conceito da democracia atrelada à base da economia de mercado, destitui-se seu caráter social e institui-se o mercado como ator principal.

Nesse novo ordenamento onde as leis de mercado se sobrepõem às questões do indivíduo social, a globalização produtiva sobrepuja o conceito de dignidade como algo próprio do ser humano, em benefício da resolução de contingências urgentes que lhe possibilite simplesmente a sobrevivência (GOMES, 2003a). Ou seja, o sentido amplo de dignidade como valores morais e espirituais próprios de todo ser humano é reduzido às questões básicas urgentes voltadas simplesmente à manutenção da vida.

Conforme afirma Bonetto e Piñero (2000, p. 205) a ascensão de um "sistema econômico assimetricamente interdependente", as políticas econômicas neoliberais bem como as novas tecnologias produtivas, colocam em crise todas as conquistas construídas no mundo do trabalho nas décadas imediatamente anteriores, deixando obscuro o novo modelo que emerge dessas transformações.

Em caráter local, ascende os discursos acerca da imperiosa necessidade de flexibilização do aparato regulatório das relações de trabalho em busca de redução dos custos de produção. Esse discurso tem assumido o eixo central nesse movimento de transformações, entretanto, enseja questões que vão muito além da rentabilidade econômico-produtiva, mas, envolvem ainda variáveis como crise de atuação do Estado, dentre outras (BONETTO; PIÑERO, 2000).

A globalização então aproxima os discursos liberalizantes que pregam a flexibilização das relações do trabalho, o que por si representa minimamente a 
perda de conquistas históricas que de alguma forma protegiam o sujeito trabalhador das desigualdades inerentes à relação capital - trabalho, com larga vantagem para esse segundo. Isso impõe aos legisladores um amplo contexto de práticas internacionais, que interferem diretamente na promulgação de leis locais, fato que propicia um alinhamento legislativo global, que à sombra do liberalismo tende à adoção de práticas precarizantes dos postos de trabalho que restam (GOMES, 2003a).

Todo esse novo cenário imprime às empresas um grau de competitividade extremo, com claras mudanças nas linhas de produção, com destaque para o conceito de produtividade e de qualidade, bem como a ascensão de um modo de produzir mais mecanizado e menos intensivo em pessoal. Aos postos de trabalho que restam dessa nova estruturação, surge a demanda por um novo tipo de trabalhador, melhor formado, com visão ampla dos processos, atributos esses que não são comuns à grande maioria dos indivíduos que se ocupam da produção até então comum de bens materiais (GOMES, 2003a).

Ainda Gomes (2003a) declara que ao mesmo tempo, é cada vez mais presente a produção de bens considerados intangíveis, cuja produção demanda intensivamente o intelecto, em especial no campo da tecnologia da informação. Com essas mudanças, desenha-se um quadro de diminuição maciça de postos de trabalho tradicionais, conjugado ao surgimento de novos produtos imateriais que ocupa uma parcela seleta da população no seu processo produtivo, ou seja, uma parcela grande da população mundial ou está condicionada ao desalento do desemprego estrutural ou está submetida às novas formas de exploração humana advindas da "lógica avassaladora do capital transnacional".

Diante desses fatos, urge a observância dos pontos da Carta Magna brasileira de 1988, no que concerne à posição desta frente à significância do trabalho para o homem no contexto da sociedade brasileira. Primeiramente a Constituição Federal (CF) elege como um de seus princípios fundamentais "a dignidade da pessoa humana" (art. $1^{\circ}$, III) e a coloca como fim da ordem econômica (art. 170, caput) (BRASIL, 2010).

Aponta como fundamento da República Federativa do Brasil, "os valores sociais do trabalho e da livre iniciativa" (art. $\left.1^{\circ}, \mathrm{IV}\right)$ e ainda como fundamentos da ordem econômica a "valorização do trabalho humano e livre iniciativa" (art. 170, caput). O trabalho é presente como direito social 
no artigo $6^{\circ}$, caput da CF. No artigo $5^{\circ}$ inciso XIII, garante-se a liberdade ao "exercício de qualquer trabalho ofício ou profissão". Nas disposições sobre a Ordem Social, o artigo 193 discorre que "A ordem social tem como base o primado do trabalho [...]” (BRASIL, 2010).

Partindo-se do pressuposto que o trabalho é o meio pelo qual o homem garante a manutenção digna e a multiplicação da vida, e dado o novo contexto de desestruturação global do mundo do trabalho, a questão que se propõe é a seguinte: - Quais as dissonâncias criadas pela nova ordem econômica internacionalizada, perante os ditames do art.170 (caput) da Constituição Federal, que funda a ordem econômica brasileira na valorização do trabalho humano? Assim sendo, o objetivo desse artigo é de aprofundar a questão acerca do distanciamento de fundamentos básicos da Constituição Federal brasileira que circunscrevem a questão do trabalho, em especial o disposto no Art. 170 em seu caput, perante o novo ordenamento econômico globalizado, que assume um caráter desestruturante do aparato protetor criado pelo esforço de décadas de conquistas trabalhistas.

Para tanto, far-se-á uma contextualização acerca dos fatores ligados à desestruturação do mundo do trabalho, posteriormente levantar-se-á o papel do Estado frente ao movimento desestruturante bem como as questões constitucionais circunscritas aos ditos do art. 170 e por fim as considerações finais sugerindo os pontos de interseção entre a proposta constitucional e a realidade presente. Metodologicamente, trata-se de uma pesquisa explicativa realizada por levantamento bibliográfico em obras e artigos correlatos ao objeto do estudo.

\section{AS TRANSFORMAÇÕES NO MUNDO DO TRABALHO}

A despeito do crescimento econômico observado na década de 1970 com criação e avanços na questão do emprego, a década de 1980 obteve resultados contrários, com aumento consequente no desemprego. A questão que se põe, refere-se à causa desse fato. Contextualmente o ressurgimento do desemprego está ligado à ascensão do liberalismo econômico e portanto, políticoideológico, ou está ligado à dita $3^{\mathrm{a}}$ Revolução Industrial e portanto é estrutural? (SINGER, 2003).

Ainda conforme o mesmo autor, a terceira Revolução Industrial em curso tem gerado avanços na produtividade e no consumo, mas, uma tendência de 
queda na oferta de postos de trabalho, à medida que boa parte dos serviços estão sendo autoexecutáveis. Considera-se ainda uma descentralização do capital, à medida que empresas verticalmente integradas partem para a prática de terceirizações com benefícios monetários para as mesmas e empresas horizontalmente estruturadas por pressão da concorrência, partem para uma modelagem de rede (franqueamento).

O grande problema é que esse movimento combinado, principalmente às terceirizações, propiciam o aumento de ocupações autônomas sem proteção legal e portanto, de baixa qualidade. Não obstante, os postos de trabalho que restam são os mecanicistas que no médio prazo produzem uma força de trabalho extremamente condicionada incapaz de evoluir.

Conforme informações dispostas pela Câmara dos Deputados (BRASIL, 2013) tramita no Congresso Nacional Brasileiro o projeto de Lei 4330/04 de autoria do Deputado Sandro Mabel, que regulamenta as terceirizações nos serviços público e privado. Prevê o projeto, que também as atividades fins das empresas serão passíveis de terceirização, ficando a empresa contratante como responsável subsidiariamente pelas obrigações trabalhistas referentes ao período em que ocorrer a prestação de serviços. De certa forma, trata-se de uma situação que aprovada pode significar maior precarização de postos de trabalho no caso do Brasil.

A premissa nesse caso é de que esse movimento de terceirização fará proliferar pequenas e desestruturadas empresas prestadoras, que ofertam postos de trabalho com menores benefícios, quando não precários e marginais ao aparato protetor, quando comparados a vagas ofertadas por empreses mais estruturadas.

Na visão de Castells (1991 apud BONETTO; PIÑERO, 2000) um dos fatores mais relevantes na explicação das mudanças ocorridas no mundo do trabalho é justamente o avanço tecnológico, fator que está redesenhando uma nova relação entre capital e trabalho, com claras perdas para esse último.

Para Bonetto e Piñero (2000) esse novo paradigma produtivo, imprime mudanças socioeconômicas, no sentido de maior flexibilização das formas de produção, consumo e gestão. Dessa forma, o advento dessas novas tecnologias aplicadas à produção, representa a necessidade de um novo modelo de trabalhador, que deve deter uma especialização flexível no lugar de uma ação mecânica característica do sistema Fordista de produção.

De acordo com Oliveira (2012), esse processo de reestruturação produtiva em busca de competitividade dentro do ambiente globalizado, vem 
acompanhado também por uma nova estrutura organizacional, conhecida por reengenharia do trabalho, que envolve a descaracterização do tradicional conceito de empregado.

Segundo o mesmo autor, essas modificações no setor produtivo resultam na escassez de postos de trabalho, bem como no surgimento de outros conceitos de trabalho diferentes do tradicional vínculo de emprego que parece não mais atender aos anseios do novo paradigma produtivo.

Na proposta de Singer (2003), o movimento de Globalização produtiva e comercial por que se está passando, também é fator de contingencia à criação de postos de trabalho. Países exportadores de capital, por exemplo, e importadores de produtos industrializados, possuem diminuída capacidade de gerar empregos, à medida que passa a importar o que antes era produzido, relegando boa parte de sua força de trabalho ao chamado desemprego estrutural, onde o trabalhador depara-se simplesmente com a extinção de sua função e não possui especialização para exercer outra. Assim sendo, a $3^{a}$ Revolução Industrial somada à Globalização extinguem postos de trabalho tanto em países desenvolvidos como nos países em desenvolvimento, o que deixa globalmente a relação entre demandantes e ofertantes da força de trabalho muito mais favorável à primeira parte.

Bonetto e Piñero (2000) chamam atenção ainda para o fato da desintegração do "Estado do Bem Estar" Keynesiano, que de certa forma assegurava ao trabalhador uma proteção social, bem como sua permanência no sistema de consumo, e todo um aparato de regulação do trabalho, o que representava maior resguardo da parte mais fraca na relação capital trabalho. Não obstante, a atuação estatal nas mediações das relações de trabalho, significava certa rigidez à imperiosa flexibilização exigida no contexto do novo paradigma produtivo. Porquanto, a ascensão de uma posição política neoliberal, implica no afastamento do Estado frente às novas relações de trabalho, expondo os trabalhadores às mazelas da hegemonia capitalista.

Conforme concluem os mesmos autores, tanto o advento das políticas neoliberais, quanto às novas tecnologias presentes no paradigma produtivo moderno, representam a destruição e precarização de postos de trabalho, com consequentes mudanças no sistema social. Não despreza os benefícios que as novas tecnologias potencialmente poderiam gerar para o indivíduo, entretanto, não se podem negar as consequências que efetivamente decorrem. 


\section{AS MUDANÇAS NA ATUAÇÃO DO ESTADO E SEUS REFLEXOS PARA O MUNDO DO TRABALHO}

Na regulação da relação capital X trabalho, urge a definição de um aparato legal capaz de delimitar direitos e deveres de ambas as partes, de cuja tarefa encarrega-se o Estado através de instrumentos que lhe são conferidos para tanto. De certa forma essa atuação do Estado é limitadora da autonomia individual e ou coletiva (também da atuação sindical) em operar decisões próprias nesse âmbito (GOMES, 2003a).

Ainda de acordo com o mesmo autor, não seria conveniente de qualquer forma, destinar à vontade humana a possibilidade de arbitrar contra seus próprios direitos fundamentais, em especial no que concerne ao mundo do trabalho. Ao contrário, os direitos fundamentais que protegem a dignidade do trabalhador merecem antes de tudo, constante atenção a seu cumprimento, na promoção da justiça social e na sua aplicação equânime.

Assim sendo, tem o Estado papel central na promoção, proteção e garantia de aplicação do regrário voltado à proteção do trabalhador. No entanto, o próprio Estado à sombra da lógica globalizante, ao propor suas leis defronta-se com a tendência de adoção de práticas universais que descaracterizam o atendimento às demandas locais, práticas essas comumente liberalizantes, precarizantes e privatizantes do aparato protetor do trabalho. Não obstante, o que se percebe é justamente um afastamento do Estado, como regulador da relação capital X trabalho (GOMES, 2003a).

Conforme aponta Bonetto e Piñero (2000) em meio ao cenário de globalização, estabelece-se uma nova relação entre Estado e sociedade, na lógica das condições capitalistas hegemônicas, que afeta diretamente o mundo do trabalho. Visivelmente essa nova relação compreende um afastamento do Estado como agente de fomento do desenvolvimento econômico e social, o que encerra uma revisão do papel econômico do Estado, com clara tendência de redirecionamento de sua atenção para o atendimento das demandas do capital industrial, em especial na infraestrutura produtiva e de serviços.

Os mesmos autores colocam ainda que este movimento de afastamento do Estado das relações sociais, toma um caráter ainda mais crítico na América Latina, à medida que ocorre não somente uma reformulação do modo relacional do Estado, mas um desmantelamento do mesmo, com ênfase em sua redução de tamanho. O que fica evidente é a diminuição da capacidade de regulação pública por parte do Estado, em busca de maior inclusão e integração social. 
Então o que resta desse movimento é a combinação de um Estado enfraquecido frente a um sistema produtivo desenvolvido com bases tecnológicas de ponta.

Nas considerações de Sarlet (2010) no que se refere ao papel do Estado na promoção da justiça social, a globalização afeta em especial os países em desenvolvimento os quais desprovidos de poder de barganha e resistência à hegemonização do pensamento liberalizante, refletindo-se inclusive no estabelecimento das novas Constituições, bem como sobre o direito individual de cada Estado.

Para Bonetto e Piñero (2000, p. 207), um aspecto importante refere-se também à "diminuição da capacidade de regulação pública, por condicionamentos internos, sobretudo pela erosão dos acordos de parceria". Refere-se em especial à estratégia de regulação das relações socioeconômicas entre os agentes sociais, suportada por uma "parceria social" abalizada pelo Estado, como forma de manutenção da paz social. De acordo com Lanzaro (1991 apud BONETTO; PIÑERO, 2000) a coalizão entre o Estado, as organizações do capital e do trabalho, possibilitou o que se entende por "triângulo corporativo", o que institucionalizou o "conflito no modelo nacional-popular".

Não obstante, vale lembrar que o Estado do bem-estar firmou-se em especial pela sua atenção às "demandas distributivas", sustentada na sua capacidade de ação frente à parceria Estado, empresas e sindicatos. Entretanto, o que se evidencia é a retirada do Estado como mediador dessa coalizão, o que implica necessariamente a desconstrução da força que equilibrava a assimetria da relação capital $X$ trabalho, com larga vantagem para esse último. A ação estatal volta-se para uma atuação mais autônoma (BONETTO; PIÑERO, 2000).

Ainda conforme os mesmos autores esta nova posição de atuação autônoma do Estado está condicionada à influência dos atores sociais que possuem maior poder barganha, como por exemplo, as organizações empresariais, sobre a ação dos tecnocratas do governo, estes agora "legitimados para solucionar problemas econômico-sociais". De certa forma, a consequência de todo esse movimento, percebe-se em especial na América Latina, pelo aumento da informalidade no trabalho, que por fim resulta na desarticulação da classe trabalhadora, debilitando sua representatividade sindical (BONETTO; PIÑERO, 2000).

Na opinião de Oliveira (2012), paradoxalmente, apesar de pregar o afastamento do Estado, o movimento neoliberal não abandona a busca do pleno emprego na economia, ao contrário, a lógica do mercado capitalista liberal, deseja que o equilíbrio gerado pelo pleno emprego ocorra de tal sorte que 
possibilite a manutenção do próprio sistema, à medida que promoveria o crescimento econômico.

O mesmo autor considera ainda imprescindível para a efetividade dos preceitos liberais, que haja consonância do raciocínio lógico do pleno emprego e a efetiva realidade fática, equilíbrio que somente seria possível sob a intervenção do Estado, o que por si representa um paradoxo à proposta liberal de afastamento do Estado.

\section{O PARADIGMA DA COMPETITIVIDADE E A FLEXIBILIZAÇÃO DO APARATO LEGAL PROTETOR DAS RELAÇÕES DE TRABALHO}

Há que se colocar que talvez o termo mais apropriado para se designar o que ocorre com a questão do emprego no mundo seja propriamente o termo precarização. Sobretudo advinda do movimento que troca postos de trabalhos formais pela prestação de um serviço autônomo sem qualquer contrato, ou mesmo pelas terceirizações de serviços secundários, fato que aumenta a atuação de pequenas empresas muitas vezes geradoras de postos de trabalhos informais legalmente desprotegidos (SINGER, 2003).

O mesmo autor considera que empregos estáveis são assegurados a um núcleo de trabalhadores de alta qualificação ao redor do qual se gira postos instáveis quando não terceirizados. Não obstante, a atuação dos sindicatos de certa forma foi sendo descaracterizada à medida que a globalização gerou mobilidade ao capital, que passa a migrar para regiões onde a atuação dessas instituições ainda são mais tímidas.

A precarização de postos de trabalho gera a priori um aumento da exclusão social à medida que para os desempregados o aumento do tempo de desemprego, relega boa parte dos indivíduos à manutenção somente de questões ligadas à sobrevivência, além do período de cobertura do seguro, e ainda para os empregados restam postos de trabalho de baixa qualidade, muitos deles marginalizados da legislação protetora e de direitos historicamente adquiridos. Também os trabalhadores por conta própria tendem a aumentar cada vez mais seu tempo de trabalho a fim de promover a manutenção de seu baixo padrão de vida (SINGER, 2003).

O novo paradigma produtivo sob a ótica da globalização, exige das empresas um novo planejamento para inserir-se no contexto árido da competição mercadológica, incluindo mudanças na forma de produzir e administrar, com 
claras consequências nas políticas de pessoal. Com vistas na maior produtividade e qualidade, a demanda das empresas é por um trabalhador melhor formado, com visão multidisciplinar, capaz de adaptar-se às novas exigências do contexto competitivo. (GOMES, 2003b).

Ainda na visão da mesma autora, o nível de desenvolvimento tecnológico está sobrepujando a produção material para segundo plano, com clara ascensão da produção de bens imateriais, em especial no campo da Tecnologia de Informação. Então o trabalhador braçal comum ao antigo paradigma produtivo está sendo substituído pelo trabalhador intelectual mais especializado, fato que encerra novas formas de exploração do trabalho humano.

O trabalhador dispensado por baixa qualificação ante as novas exigências do mercado vê-se impossibilitado de retornar ao sistema, até mesmo pela incapacidade de adequar-se, e acaba por engordar o chamado desemprego estrutural. Todo esse processo traz consigo a demanda por uma nova ordem jurídica, onde figura a ausência do Estado e a minimização do aparato legal protetor das relações de trabalho.

O desemprego estrutural é resultante do movimento de modernização das estruturas produtivas que ocorre com a mecanização e automação nos processos de produção. Postos de emprego são substituídos por máquinas modernas que são capazes de realizar o trabalho de muitas pessoas ao mesmo tempo, extinguindo definitivamente muitas vagas de emprego (POCHMANN, 2001).

O mesmo autor adverte que o trabalhador no desalento, incapaz de adaptar-se a outras tarefas, frente às exigências de um trabalhador mais qualificado e multifacetado, permanece no desemprego estrutural, muitas vezes aumentando o setor informal da economia, ocupando vagas precarizadas do subemprego.

Esse é o caráter do novo paradigma produtivo e concorrencial hegemônico. A geração de segregados sociais, sem acesso ao sistema de proteção que lhe confira um mínimo de dignidade. A exclusão social é ainda maior, à medida que os ganhos de produtividade se sustentam sobre a degradação salarial daqueles que continuam inseridos no sistema. Complementa ainda Gomes (2003b, p.106):

Decorre daí a encruzilhada em que o cidadão-trabalhador, quando não é excluído e condenado ao universo da informalidade, é integrado e submetido à lógica avassaladora do capital transnacionalizado. O fenômeno tem 
impulsionado os governos para uma revisão daquele modelo estatal que se corporificou a partir do início do Século XX, com intervenções flagrantes na economia ao lado da extensiva atividade regulamentadora, mormente no âmbito das relações de emprego. Propugna-se então pela flexibilização ou até mesmo pela desregulamentação das leis trabalhistas.

Não obstante há que se considerar a previsão constitucional para a flexibilidade de direitos trabalhistas, com exceção dos direitos básicos e irrenunciáveis, bem como as condições para tanto, conforme os ditames do art. $7^{\circ}$, VI, XIII e XIV. Entretanto a construção do Direito do Trabalho se deu sob anos de conquistas da classe e seus efeitos sustentado no "dirigismo contratual", sobretudo na relação entre empresa e trabalhador. Desregulamentar as conquistas seria a própria "destruição do Direito do Trabalho" (GOMES, 2003b).

Vem consagrado, ao longo dos tempos, após sofridas lutas e conquistas (capítulo III), o princípio de proteção ao hipossuficiente - que lhe confere a superioridade jurídica em face da superioridade econômica do empregador, no seu tríplice aspecto: (1) in dúbio pro operário; (2) da norma mais favorável ao empregado e da (3) condição mais benéfica, no sentido de que uma nova norma trabalhista nunca deve diminuir ou excluir direitos adquiridos do empregado. Aliados a esse princípio básico, que serve como critério orientador do Direito do Trabalho, outros princípios de fundamental importância também informam a concreção de regras sobre os quais se apoiam, tais como, os princípios da irrenunciabilidade, da continuidade, da primazia da realidade sobre aspectos formais da relação, da razoabilidade e da boa-fé, entre outros merecedores de destaque (GOMES, 2003b, p.107).

Assim sendo, a flexibilização e a desregulamentação dos direitos trabalhistas, nos moldes imperativos na contemporaneidade, representa dentre o mais, o afastamento do Estado como regulador, fiscalizador e mediador da relação contratual de trabalho, que garante o mínimo de dignidade ao indivíduo trabalhador. (GOMES, 2003a).

Rüdiger (2005, p.378), chama a atenção para a "teoria da flexibilização", como um discurso aceito por parte de teóricos brasileiros, que tendem à proposta de flexibilizar as relações de trabalho com ênfase na negociação coletiva como instrumento resolutório das novas demanda de mercado. Analisa que há uma ligação estreita entre "o debate jurídico acerca dos fundamentos do Direito do 
Trabalho, de sua interpretação e de sua fonte privilegiada e a política da desregulamentação do mercado", que se refere em último caso a reprivatizar o mercado reprivatizando o direito, e complementa:

A flexibilização do Direito do Trabalho com foco na negociação coletiva passa ser "[...] o instrumento de política social caracterizado pela adaptação constante das normas jurídicas à realidade econômica, social e institucional, mediante intensa participação de trabalhadores e empresários, para eficaz regulação do mercado de trabalho", como reza a obra mais representativa da teoria da flexibilização no Brasil, a de Luiz Carlos Amorim Robortella (1994, p. 97), que, de maneira bastante eloquente, intitula-se O Moderno Direito do Trabalho.

Segundo a mesma autora, há um duplo caráter na flexibilização do Direito do Trabalho, envolvendo de um lado a questão de um conjunto de normas que limitam o poder do capital e de outro a questão da liberdade do mesmo capital através da intervenção mínima do Estado. Nas palavras de Robortella (1994, p. 98 apud RÜDIGER, 2005, p. 379) a flexibilização garante a “[...] produtividade da mão-de-obra, competitividade, modernização, mercado, lucro e desenvolvimento econômico".

A questão que surge no debate é o desemprego gerado pela globalização econômica, pela racionalização produtiva e pela reestruturação da nova forma de produção. O que se percebe é que o discurso flexibilizante aparece como a possibilidade de correção desse desemprego, quando na verdade, a dimensão do debate envolve mais as questões de sobrevivência do próprio capital dentro do novo cenário competitivo, bem como a possibilidade oportuna de se ver livre do Direito do Trabalho, considerado sistematicamente um empecilho à liberdade capitalista (RÜDIGER, 2005).

Para Gomes (2003b, p. 108) se há imperiosa necessidade de flexibilizar os direitos trabalhistas, o que se deve proteger é antes de tudo o próprio homem. Não obstante, frente o constante na Carta Magna Brasileira de 1988 com intuito de proteção à pessoa humana, o trabalho possui posição de destaque. Tratado como "um dos fundamentos do Estado Democrático do Direito (art. $1^{\circ}, \mathrm{IV}$ ). Além disso, a mesma Lei Maior proclama que a ordem econômica deve ser fundada na valorização do trabalho (art. 170) e a ordem social tem por base o primado do trabalho (art. 193)".

Para a mesma autora, cabe à sociedade civil organizada, diante de seus agentes como sindicatos, instituições que representam classes de trabalhadores, 
partidos políticos, federações e outros, questionar-se acerca dos limites que desejam flexibilizar as regras de tutela do trabalho, mas, sempre buscando como centro do debate o resguardo da dignidade da pessoa humana assim como a garantia da cidadania.

Quanto ao desemprego estrutural não se estabeleceu ainda uma solução definitiva, entretanto, é inegável que a criação de postos de trabalho depende antes de tudo da possibilidade de crescimento econômico, mas, fundado no aumento da educação da população com consequente qualificação da mão de obra, aperfeiçoamento do aparato sindical, e uma readequação do papel econômico do governo (GOMES, 2003a).

Ainda na opinião da mesma autora, a atuação legislativa deve ser pautada não pela questão envolvendo escolhas em beneficiar poucos grupos econômicos ou a sociedade comum. Antes, deve-se pautar pela promoção do acesso da população aos instrumentos educacionais de qualidade, que possibilitem uma melhor formação cultural e política do cidadão, efetivando a construção de uma sociedade mais participativa e crítica de seus direitos, em especial os constitucionais.

\section{OS PRINCÍPIOS DA VALORIZAÇÃO DO TRABALHO HUMANO E DA DIGNIDADE DA PESSOA HUMANA NO CONTEXTO DA DESESTRUTURAÇÃO DO MUNDO DO TRABALHO}

Dentro de todo o contexto apresentado que situa as mazelas geradas pelo movimento de globalização e modernização produtiva, no plano do mundo do trabalho, urge resgatar, conforme as proposições de Gomes (2003a) "a tomada de consciência a respeito da pessoa humana como valor-fonte de todos os valores".

Primeiramente referindo-se à questão da dignidade da pessoa humana, esta advém em especial, do fato de pertencer ao homem, distintamente de todas as outras criaturas, a posse da razão e da consciência. Não obstante aos preceitos ligados à tradição cristã de que o homem "relaciona-se com um Deus que também é pessoa" (GOMES, 2003a).

Considera ainda ser a própria justiça, um conceito ligado à natureza da pessoa humana, e indispensável na manutenção da paz social coletiva. O direito estaria portanto, fundado na natureza e não no arbítrio. Para Sarlet (2001 apud GOMES 2003a) seria ainda a dignidade da pessoa humana o próprio fim e não 
um meio, o que por si enfraquece toda e qualquer linha de pensamento destinada a legitimar uma visão de instrumentalização do ser humano.

Na visão de Delgado (2006, p.152), este princípio é a expressão da centralidade que o próprio Direito, o Estado e a sociedade tem no ser humano, independente de posição social, econômica, ou de qualquer outro condicionante que possa ser parâmetro para segregar um indivíduo, mas, antes com foco na sua essencialidade.

Assim, a dignidade da pessoa humana não pode ser vista como uma criação constitucional. Trata-se antes, de um conceito pré-existente, um valor próprio da natureza humana. Entretanto, a tomada de consciência desse valor deu-se num processo histórico que culmina na promulgação desse valor nas Constituições modernas baseadas nos preceitos democráticos (GOMES, 2003a).

O princípio da dignidade da pessoa humana traduz a ideia de que o valor central das sociedades, do direito e do Estado contemporâneos é a pessoa humana, em sua singeleza, independentemente de seu status econômico, social ou intelectual. O princípio defende a centralidade da ordem juspolítica e social em torno do ser humano, subordinante dos demais princípios, regras, medidas e condutas práticas.

Trata-se do princípio maior do Direito Constitucional contemporâneo, espraiando-se, com grande intensidade, no que tange a valorização do trabalho (DELGADO, 2006, p.152).

A preocupação de garantia e proteção dos direitos humanos, expressa nas Constituições modernas, caracteriza de certa forma o Direito como agente transformador da sociedade. Nesse ínterim, concretiza-se um conjunto de regras e normas que limitam o poder de atuação do Estado Democrático, à medida que coloca a dignidade da pessoa humana como o caráter constitucional centralizador de todos os direitos fundamentais (GOMES, 2003a).

Na perspectiva da mesma autora, os direitos fundamentais representam a centralidade de todo ordenamento constitucional. Uma série de metas que o Estado Democrático de Direito deve obrigatoriamente atingir, por representar um construto histórico baseado nos anseios da coletividade.

Assim, no Estado Democrático de Direito, onde a Constituição Federal não só reconhece a existência e a eminência da dignidade da pessoa humana, mas a transforma em valor supremo de ordem jurídica, não se pode dar atenção apenas aos interesses da economia que condicionam a atuação 
governamental, deixando o trabalhador vagar solitário no meio das leis do mercado. Inexoravelmente, ele deve ser visto como detentor de direitos fundamentais, amparado por normas pétreas da Constituição, que não podem ser afastadas nem eliminadas por Emenda Constitucional (GOMES, 2003a, p. 126).

Na visão de Sarlet (2010), os direitos fundamentais por sua essencialidade (formal e material) demandam normatividade e proteção da ordem jurídica superiores, relativamente às demais normas constitucionais. Mesmo por isso, os direitos fundamentais foram na Constituição brasileira de 1988, erigidos, se não na sua totalidade, mas, em parte, à condição de cláusula pétrea, integrando o disposto no art. $60, \S 4^{\circ}, \mathrm{IV}$, que se constituem em contingências às reformas constitucionais.

A dignidade da pessoa humana é destacada no texto constitucional, tanto como fundamento da República Federativa do Brasil (art. $1^{\circ}$, III) como também, fim da ordem econômica, dito no atr. 170, caput - "a ordem econômica ...tem por fim assegurar a todos existência digna" (BRASIL, 2010). Nos dito de Grau (2012), “... a dignidade da pessoa humana, enquanto princípio, constitui ao lado do direito à vida, o núcleo essencial dos direitos humanos".

No que concerne ainda ao texto constitucional, este aponta em seu art. $1^{\circ}$, IV o valor social do trabalho como fundamento da República Federativa do Brasil, e por outro lado, no art. 170, caput, funda a ordem econômica na valorização do trabalho humano. Da interação desses dois princípios urge fundamentalmente que cabe ao trabalho e seus agentes a dispensa de um trato peculiar. Esse trato materializa-se no ponto em que o trabalho passa e encerrar atenção política racional (GRAU, 2012).

Conforme o mesmo autor, há intrínseca divergência de interesses entre os atores do capital e do trabalho, apesar de se tentar demonstrar o contrário. Na conciliação de ambos, urge a atuação do Estado, que imbuído dos princípios da valorização do trabalho humano bem como do valor social do trabalho e de suas interações com os demais, encarrega-se então da "prevalência dos valores do trabalho na conformação da ordem econômica".

Considera-se então, aceito no âmbito deste artigo, que o acesso ao trabalho na sua forma clássica dentro do padrão protecional que o circunscreve, é promotor da dignidade humana. Como dito por Delgado (2006, p. 146), a afirmação constitucional do trabalho na ordem jurídico-cultural brasileira se faz principalmente por quatro princípios: "o da valorização do trabalho, em especial 
do emprego; o da justiça social; o da submissão da propriedade à sua função socioambiental; o princípio da dignidade da pessoa humana".

$\mathrm{Na}$ concepção de Gomes (2003a) considerando a natureza humana, a garantia dos direitos fundamentais somente se dá mediante um aparato grande de regras capazes de limitar a atuação avarenta dos agentes ligados à propriedade, na busca de explorar os mais fracos que vendem sua força de trabalho. Mesmo na contemporaneidade, não há por parte do ser humano uma atitude concisa na busca de uma sociedade realmente justa. Daí a prevalência da exploração do hipossuficiente.

Ainda na mesma autora, atenta-se que a evolução da exploração do homem que destituído de sua dignidade, vê-se escravo da máquina e da ânsia da classe empresária que lhe impõe condições adversas de trabalho. Então, as relações econômicas personalizam-se antes de tudo em relações de força, causadoras dos desequilíbrios sociais provocados pelo capitalismo.

Atenta-se porém, para o fato de que constitucionalmente o trabalho "traduz-se em princípio, fundamento, valor e direito social". Cabe porém destacar que sob a ótica constitucional, conduz-se como expressão correta a valorização do trabalho "regulado" como sendo esse o principal meio de afirmação socioeconômica do indivíduo frente a seus congêneres (DELGADO, 2006, p. 149).

Sob a máxima do "Laissez Faire" o Estado liberal insere-se nesse contexto como mero expectador, garantindo a ordem política e social, terreno fértil à expansão do capitalismo que soberano, comanda o desenvolvimento da sociedade sem qualquer incursão ética e moral (GOMES, 2003a). Na percepção de Grau (2012), mesmo com caráter liberal que permeia a Constituição Federal de 1988, o intervencionismo estatal está em favor de garantir a justiça social. Isso não encerra uma duplicidade interpretativa (liberal X intervencionista) da Constituição Federal.

Não obstante, nas afirmações de Sarlet (2010) a globalização econômica e o discurso neoliberal tem um impacto visível personalizado na busca reformista dos direitos fundamentais com consequentes pressões sobre os direitos sociais. Isso atinge de forma especial a ordem jurídica-constitucional no que se refere ao direcionamento das reformas constitucionais, em especial de países em desenvolvimento que possuem menor poder de barganha e resistência frente ao capital. Por isso as tendências de flexibilidade do aparato protetor do trabalho.

Por outro lado evidencia-se também que as mudanças no modo de produção, advindas da globalização, fragmentou e descentralizou a classe 
trabalhadora, entre aqueles com emprego fixo, os relegados à informalidade, os temporários dentre outros tantos, fato que contingenciou contumaz a atuação sindical, na busca de uma unidade representativa, o que poderia oferecer resistência às pressões flexibilizantes dos direitos dos trabalhadores (BONETTO; PIÑERO, 2000).

Para as mesmas autoras, o Estado não consegue mais responder às demandas populares, e a atuação sindical atravessa uma crise expressiva não apenas advinda das dificuldades de reunião da classe, como também, da sua própria organização e operacionalização interna. O resultado dessa combinação reflete-se em especial na incapacidade de construir uma representação que proteja os direitos trabalhistas conquistados ao longo de décadas de lutas da classe.

\section{CONSIDERAÇÕES FINAIS}

É inegável que a globalização econômica impôs às empresas um nível concorrencial elevado, onde é imperativa a busca por maior competitividade nesse novo mercado. A busca por supressão nos custos de produção torna-se então imperiosa. Entretanto, essa busca ascendeu de um de um discurso universal neoliberal, que apregoa a flexibilização dos direitos trabalhistas, e o afastamento do Estado como mediador das relações capital X trabalho, com perdas sociais substanciais para esse último.

Conjuntamente, o advento do que se denomina $3^{\text {a }}$ Revolução Industrial, proporcionou um avanço tecnológico expressivo no setor produtivo, o que possibilitou ganhos em produtividade e resultou na racionalização do processo produtivo com consequente perda de postos de trabalho, substituídos por máquinas. Esse movimento vem acompanhado pela demanda por um novo tipo de trabalhador, com maior especialização, fato que encerra no desalento de boa parte da mão de obra incapaz de acompanhar essas novas exigências.

Assim, o desemprego estrutural é resultado do movimento de reestruturação produtiva e do trabalho que ocorre com a mecanização e automação nos processos de produção. Postos de trabalho são substituídos por máquinas capazes de realizar o trabalho de muitas pessoas, extinguindo definitivamente vagas de emprego.

$\mathrm{O}$ trabalhador incapaz de se adaptar à nova realidade permanece no desalento, aumentando o setor informal da economia e alimentando um mercado de vagas de emprego precário, o que depõe contra o princípio 
constitucional de valorização do trabalho humano, bem como da dignidade da pessoa humana.

Não obstante, a reestruturação produtiva, cria novas formas de relação de trabalho, que diferem do tradicional conceito de emprego, e distancia-se fatalmente do tradicional aparato legal de proteção ao trabalho. As novas formas de exploração contribuem contumaz à queda na qualidade dos postos de trabalho que surgem, bem como, descaracterizam relações institucionalizadas de emprego, portanto, limitam a aplicação de regras protetoras do trabalho.

No entanto o discurso acerca da flexibilização dos direitos trabalhistas como forma de diminuição de custos produtivos, deve ser para o Direito, antes, um questionamento acerca do desemprego e da precarização de postos de trabalho, gerados pelo novo paradigma produtivo.

O trabalho como gerador da própria vida, é meio pelo qual se afirmam princípios fundamentais da Constituição Federal Brasileira, ditos nos seus $\operatorname{artigos} 1^{\circ}, 3^{\circ}, 6^{\circ}, 170$ dentre outros, e como tal, deve-se o valor. Entretanto, a valorização do trabalho humano enseja antes a necessidade de ser este livre, de qualidade, e protegido no sentido de equalizar a grande diferença de poder intrínseca nas relações entre capital e trabalho. Não obstante, o papel do Estado mediador estaria a essa função.

Cronologicamente, a questão da participação do Estado na economia, aponta diferentes momentos. No entanto a década de 1980 foi marcada pelo ressurgimento do movimento liberal, denominado neoliberalismo, o qual apregoa o afastamento do Estado das relações econômicas. O distanciamento da instituição estatal das relações sempre desiguais entre capital $\mathrm{X}$ trabalho, significa para esse último como parte hipossuficiente, sua submissão total às regras do jogo capitalista, com consequente deterioração de todas as conquistas protecionistas feitas ao longo de anos de luta.

Mesmo sob o caráter liberal presente na Constituição Federal de 1988, o resguardo da dignidade da pessoa humana, como fundamento da República Federativa do Brasil e como fim da ordem econômica, enseja que qualquer atividade não voltada a essa premissa estará contrária ao texto constitucional. Atenta ainda que dos fundamentos constitucionais da ordem econômica na valorização do trabalho humano e na livre iniciativa, destaca que o ator principal está centrado no "trabalho humano".

Enfim, o objetivo deste artigo como pesquisa exploratória, foi situar contextualmente a ocorrência de mudanças estruturais ocorridas na evolução 
do modo de produção capitalista contemporâneo, com vistas no advento da $3^{\mathrm{a}}$ Revolução Industrial em conjunto com a ascensão do neoliberalismo, ante os princípios constitucionais da dignidade da pessoa humana e da valorização do trabalho humano.

Percebe-se o quão danoso para o mundo do trabalho é o afastamento do Estado como força mediadora do equilíbrio entre a relação capital X trabalho, em especial nesse contexto do advento de novas relações de emprego, precarização de vagas remanescentes e destruição de postos tradicionais de trabalho, como subprodutos do novo paradigma produtivo. Outrossim, há de se questionar frente à situação posta: qual o papel do Diretito na busca de corrigir as discrepâncias geradas no mundo do trabalho? Talvez uma proposta de continuidade do presente artigo.

\section{REFERÊNCIAS}

BONETTO, M. S.; PIÑERO, M. T. Las transformaciones em el mundo del trabajo: la reconfiguracion del sujeto trabajador. Revista Crítica Jurídica, Córdoba, n.17, ago. 2000.

\section{BRASIL. Consolidação das Leis do Trabalho; Código do Processo} Civil; Legislação Previdenciária; Constituição Federal. 5. ed. São Paulo: Saraiva, 2010.

BRASIL. Câmara do Deputados (BRASIL). Projetos de leis e outras proposições. Disponível em:〈http://www.camara.gov.br〉. Acesso em: 15 ago. 2013.

DELGADO, M. G. Direitos fundamentais na relação de trabalho. Revista de Direito e Trabalho, São Paulo, ano 32, n.123, jul-set. 2006.

GOMES, D. G. P. A dignidade do trabalhador no cenário da globalização econômica. Revista do Tribunal Regional do Trabalho da $9^{\text {a }}$ Região, Curitiba, v.28, n.49, jan./jun. p.103-132, 2003 b.

GOMES, D. G. P. Princípio constitucional da dignidade da pessoa humana e a flexibilização da legislação trabalhista. Revista de Direito Constitucional e Internacional, São Paulo, p. 92-143, jul/set. 2003a. 
GRAU, E. R. A ordem econômica na constituição de 1988. 15. ed. São Paulo: Malheiros, 2012.

OLIVEIRA, L. A função social da empresa privada e a desagregação causada pelo novo modo de produção. Londrina, 2012.

POCHMANN, M. O emprego na globalização: a nova divisão internacional do trabalho e os caminhos que o Brasil escolheu. São Paulo: Boitempo, 2001.

RÜDIGER, D. S. Teoria da flexibilização do direito do trabalho: uma tentativa de contextualização histórica. Verba Juris, João Pessoa, ano 4, n. 4, jan./dez. 2005.

SARLET, I. W. Dignidade da pessoa humana e direitos fundamentais na constituição federal de 1988. 8. ed. Porto Alegre: Livraria do Advogado, 2010.

SINGER, P. Globalização e desemprego: diagnóstico e alternativas. São Paulo: Contexto, 2003.

Submetido em: 10/09/2013 Aprovado em: 23/11/2014

Como Citar: OLIVEIRA, Lourival José de; MASSARO, Marcio Luis. As mudanças contemporâneas no mundo do trabalho e o princípio da valorização do trabalho humano. Scientia Iuris, Londrina, v.18, n.2, p.189209, dez.2014. DOI: 10.5433/2178-8189.2014v18n2p189. 